\title{
The link between parenting approaches and health behavior: a systematic review
}

\author{
Eugene Lee Davids, Nicolette V. Roman \& Lloyd Leach
}

\begin{abstract}
The familial home environment, where parenting takes place, plays an important role in the health behaviors that children and adolescents engage in and has implications on health and well-being in later life. Lifestyle-related behaviors predispose children and adolescents to the global burden of non-communicable and other lifestyle-related diseases. This review therefore examined and described previous studies looking at the associations between health behaviors and parenting approaches. It suggests that engagement in health behaviors, which promotes overall health and well-being, was associated with autonomy, supportive parenting, parental encouragement, behavior control, parental nurturance, warmth and responsiveness, and parental involvement. The review highlights the gap in literature focusing on the health behavior of children and adolescents as well as on parenting. In addition, the review also provides an overview of the continents where fewer studies have examined the presented associations. The findings presented also serve as a guide for program development and implementation to address the increase in non-communicable and other lifestyle-related diseases.
\end{abstract}

\section{Background}

Understanding the health and well-being of children and adolescents has often been overlooked and neglected (Patton et al., 2016). Of late, the importance of understanding child and adolescent health has become apparent and has become a concern for global development (Mokdad et al., 2016). The dearth of empirical evidence in child and adolescent health presents a gap in our understanding (Patton et al., 2016). Attempting to understand adolescent health would allow for the development of strategies to improve health among young people-particularly as it has implications on their health in later life (Mokdad et al., 2016).

Adolescents account for just over sixteen percent of the global population (Nagata, Ferguson, \& Ross, 2016), and this developmental phase presents several health-related challenges that add to the high rates of adolescent mortality. Studies examining the high mortality rates during adolescence fail to take into consideration the important role of health behaviors, which pose a threat for positive health and well-being in adulthood (Nagata et al., 2016). The health behaviors that adolescents adopt and engage in, whether positive or negative in nature, may not always have implications on their health now; but later in life (Gore et al., 2011; Nagata et al., 2016). The development of ill- 
health as a result of health behaviors adopted and maintained throughout adolescence not only presents individual health concerns in later life, it also adds to the economic burden of government health aid.

Health behavior has been defined as the behaviors and actions that individuals engage in that concerns their physical health, nutritional and dietary practices, physical activity as well as addictive behaviors (Burusic, Sakic, \& Koprtla, 2014). Goldsteen, Goldsteen, and Graham (2011) have added to the definition of health behavior as being the behaviors that often promote positive health, yet it has been used contrary too-to refer to behaviors that are detrimental to health as noted during adolescence. These behaviors or their absence has implications on the general health status and well-being of adolescents and is an important determinant of health (Bruhn, 1988; Burusic et al., 2014; Goldsteen et al., 2011). The health behaviors, that young people engage in, are largely shaped by the environment in which they find themselves (Cohen, Scribner, \& Farley, 2000; Hanson \& Gluckman, 2015). For children and adolescents, the environment often is the parental home environment.

The parental home environment allows for the nurturance and development of children and adolescents. The parent-child relationship and interactions have been noted as having differential outcomes as a result of the quality of the parent-child relationship on the developing child and adolescent. The interactions between the parent-child dyad also have implications on the development, adoption, and maintenance of health behavior. Parenting that involves the displays of warmth and responsiveness has been associated with favorable developmental outcomes for child and adolescent health; however, the lack of parental warmth and autonomy granting has a differing effect on development.

When examining the importance of understanding adolescent health from a global perspective, the United Nation's Sustainable Developmental Goals (SDG's) provide an overarching agenda of improving health across the lifespan. However, with the lack of understanding adolescent health and the gaps which exist, the Global Strategy for the first time has included adolescents in its 2015 Global Strategy for Women's, Children's and Adolescents' Health. By understanding adolescent health from the perspective of the SDG's and the Global Strategy, it creates a platform for closing the gap in our understanding about adolescent health and its determinants. It also allows for determining how to improve morbidity and mortality rates during this developmental phase. Morbidity and mortality are often associated with the health behaviors which are shaped by the environment-the parental home environment. Taking the important role of the parental home environment into consideration and how it shapes health behavior of children and adolescents, the current article therefore aimed to review the associations between health behavior and parenting approaches. The review was framed within a health promotion perspective and broadly examined healthy lifestyle behaviors. 


\section{Methods}

\section{Terms and definitions}

The aim of the systematic review was to establish the relationship between child and adolescent health behavior and parenting approaches. The terms and definitions of health behavior and parenting approaches within the context of the systematic review are explained in Table 1.

\begin{tabular}{lc}
\hline Table 1. Terms and definitions. \\
\hline Term \\
\hline Health behavior(s) \\
Parenting approach & $\begin{array}{r}\text { The behaviors or actions that individuals engage in with the aim of promoting and } \\
\text { committing to a lifestyle that promotes health and well-being (Leddy, 2003). } \\
\text { Strategies or ways used by parents in the rearing and caring for their children } \\
\text { /offspring (Kitamura et al., 2014). }\end{array}$ \\
\hline
\end{tabular}

\section{Search strategy}

During the months of November and December 2014, a search was conducted using the following databases and journals: Science Direct, Ebscohost (Academic Search Complete, PsycArticles, Medline, SocIndex and ERIC), BioMed Central, PubMed, Directory of Open Access Journals (DOAJ) and SAGE Journals from 2004 to 2014. A 10-year period was chosen to consider studies that are deemed "recent" in the field. The review consisted of studies that examined the relationship between health behavior and perceived parenting approaches. The terms used in the search included healthy lifestyle behaviors, healthrelated behavior, health-promoting behavior, healthy behavior, health seeking behavior, parenting, parenting approaches, parenting styles, authoritative parenting, authoritarian parenting, permissive parenting, and uninvolved parenting. The titles and abstracts of the various publications were examined using the inclusion criteria for the review. The retrieval of full text articles was done by one of the reviewers (First Author), and the same process was then followed by the other reviewers (Second and Third Author) to determine whether the articles met the inclusion criteria.

\section{Inclusion criteria}

The inclusion criteria that had to be met for inclusion within the review were that the study had to (1) be published in or translated into the English language; (2) published between 2004 and 2014; (3) used either children, adolescents or youth as part of the sample; and (4) examined the relationship or association between health behavior and parenting approaches; and (5) could be either cross-sectional or longitudinal studies.

\section{Methods of the review}

The first author conducted an initial search and review of the abstracts and articles, using Boolean logic and Boolean operators. The initial search yielded 1,788 articles for the keywords healthy lifestyle behaviors and parenting. The searches thereafter, when tallied, yielded 96,729 articles for healthy lifestyle behaviors, health-related behavior, health-promoting behavior, healthy behavior, health seeking behavior, parenting, parenting approaches, parenting styles, authoritative parenting, authoritarian parenting, permissive parenting, and uninvolved parenting. During the searches, 96,546 articles were excluded from the review due to their relevance in addressing the aim of the review. In addition to the searches, the titles were also reviewed for eligibility, and a sample of 183 studies was identified. One additional study was obtained from examining the reference lists of the other articles that produced a total of 184 
articles. Next, all duplicates were removed reducing the sample to 33 articles. Duplicates were any article that appeared more than once in the list of retrieved articles across the databases searched in the review. The sample of 33 articles was independently read and assessed based on the aim of the review, and 10 articles were finally selected for inclusion in the methodological quality appraisal phase, while the remaining 23 articles were excluded from the review as it did not meet the inclusion criteria as determined at the onset of the review.

\section{Methodological quality appraisal}

An instrument was used to assess the methodological quality of the studies that met the inclusion criteria (Table 2). The instrument was adapted from previous systematic reviews by Louw, Morris, and Grimmer-Somers (2007), Wong, Cheung, and Hart (2008), Roman and Frantz (2013) as well as Davids and Roman (2014). The rationale guiding the questions in the methodological quality appraisal are discussed below.

\section{Question 1: Sampling}

The first question dealt with the sampling method employed in the study, assessing whether probability or non-probability sampling was employed. Probability sampling allowed for random selection of participants, while non-probability sampling did not involve random selection and often raised the concern about how representative the sample is of the population being studied.

Table 2. Methodological quality appraisal tool.

\begin{tabular}{|c|c|c|}
\hline Q & Item & Scoring \\
\hline Q1 & $\begin{array}{l}\text { Sampling method: Was it representative of the population intended in the study? } \\
\text { A. Non-probability sampling (including: purposive, quota, convenience and } \\
\text { snowball sampling) } \\
\text { B. Probability sampling (including: simple random, systematic, stratified, } \\
\text { cluster, two-stage and multi-stage sampling) }\end{array}$ & $\begin{array}{l}0 \\
1\end{array}$ \\
\hline Q2 & $\begin{array}{l}\text { Was a response rate mentioned within the study? (Respond no if response rate } \\
\quad \text { is below } 60 \% \text { ) } \\
\text { A. No } \\
\text { B. Yes }\end{array}$ & $\begin{array}{l}0 \\
1\end{array}$ \\
\hline Q3 & $\begin{array}{l}\text { Was the measurement tool valid and reliable? } \\
\text { A. No } \\
\text { B. Yes }\end{array}$ & $\begin{array}{l}0 \\
1\end{array}$ \\
\hline Q4 & $\begin{array}{l}\text { Was the data source primary or secondary? } \\
\text { A. Primary data source } \\
\text { B. Secondary data source (survey, not designed for the purpose) }\end{array}$ & $\begin{array}{l}1 \\
0\end{array}$ \\
\hline Q5 & $\begin{array}{l}\text { Were Healthy Lifestyle Behaviors examined in the study? } \\
\text { A. No } \\
\text { B. Yes }\end{array}$ & $\begin{array}{l}0 \\
1\end{array}$ \\
\hline Q6 & $\begin{array}{l}\text { Was the relationship or association between Healthy Lifestyle Behaviors and } \\
\quad \text { Parenting Approaches explored? } \\
\text { A. No } \\
\text { B. Yes }\end{array}$ & $\begin{array}{l}0 \\
1\end{array}$ \\
\hline Scoring: & $\begin{array}{l}\text { vided by total number of items multiplied by } 100 \text { (expressed as a percentage) } \\
\text { Methodological appraisal score }\end{array}$ & \\
\hline Bad & Satisfactory & Good \\
\hline $0-33 \%$ & $34-66 \%$ & $67-100 \%$ \\
\hline
\end{tabular}

Therefore, studies that employed a probability sampling method scored one point on the first question, while the opposite received a scoring of zero. 


\section{Question 2: Study response rate}

The second question examined whether the response rate was mentioned for the study, as the higher the response rate that a study has the lower the risk of non-response bias in the results found. Therefore, if the response rate was mentioned in the study, and it was $60 \%$ or above, it received a score of one, where if there was no response rate mentioned or it was below $60 \%$, it received a zero due to possible non-response bias.

\section{Question 3: Instrument reliability \& validity}

The third question examined the way the instrument was used. It looked at the reliability and validity of the instrument. When examining reliability, if the study examined the (1) internal consistency reliability of the items in the instrument or (2) if it employed a test-retest method to assess consistency of the instrument it scored a 1 , if it did not report assessing the reliability of the instrument in the study presented it scored a zero.

\section{Question 4: Origin of data source}

The fourth question was about the data source used to present the findings. Primary data are data that the researcher had collected him/herself (such as questionnaires developed for the specific intention of a research project), while secondary data sources are those that already exist (such as official government statistics). If it was a primary data source, it scored one point because the information/data had been collected for the intended purpose of the study, while the secondary data source received a zero.

\section{Questions 5 and 6: Associations between healthy lifestyle behaviors and parenting approaches}

The fifth question aimed to establish whether the study examined healthy lifestyle behaviors, if it did it received one point, if not a zero was allocated. The sixth question aimed to determine whether the study examined the association between healthy lifestyle behaviors and parenting approaches. If the association was examined in the study, it received one point, and failing to examine the association resulted in a zero.

After the methodological appraisal, the final sample consisted of ten articles which were included in the systematic review (Table 3) as they all met the criteria for inclusion. Figure 1 outlines the process involved in the systematic review.

\section{Data extraction and synthesis}

After the methodological quality was appraised for each of the studies, only those studies that met the criteria for the categories of satisfactory to good were reviewed. In an attempt to make sense of the data generated from the review, a narrative synthesis approach was employed. This approach to the synthesis of the findings was selected as it allowed for synthesizing of the data narratively-as the study designs were heterogeneous in nature (Guise, Anderson, \& Wiig, 2014). In addition, the use of meta-ethnographic or metaanalytic analyses did not prove to be viable alternatives in attempts to understanding the findings within the review (Guise et al., 2014).

The narrative synthesis approach employed was adapted from the recommendations by Popay and colleagues (2006) and has previously been implemented by Leamy, Bird, Le 
Boutillier, Williams, and Slade (2011), which followed a three staged synthesis approach: (1) developing a preliminary synthesis of findings of included studies, (2) exploring the relationships which exist in the data, and (3) an assessment of the robustness of the synthesis.

The first stage of developing a preliminary synthesis of the findings of the studies included in the review followed a data extraction procedure as used by Davids and Roman (2014). The data extraction procedure involved tabulating data from the studies that met the methodological quality criteria for inclusion. The information in the data extraction table included author, geographical location of study, study design, participant information, instruments used, healthy lifestyle behavior, and the relationship/association between healthy lifestyle behavior and parenting approaches (Table 4). In the second stage of the narrative synthesis, the relationships which exist within the data were explored by tabulating the associations between health behavior and parenting approaches (Tables 5 and 6). The third and final stage of the narrative synthesis involved assessing the robustness of the synthesis, this allowed for an examination of the methodological rigor and checking of data at each stage of the data collection and analysis procedures (Le Boutillier et al., 2015). To ensure robustness within the review, all articles were initially searched and assessed by the first author, and a follow-up double-search and assessment were employed by the second and third authors. The retrieved articles also involved a screening for eligibility and an assessment of the methodological quality of the articles to determine the methodological rigor of the studies to be included in the review (as discussed above).

\begin{tabular}{lcccccccc} 
Table 3. Methodological appraisal. & Q1 & Q2 & Q3 & Q4 & Q5 & Q6 & $\%$ & Decision \\
\hline Author(s) & 0 & 1 & 1 & 0 & 1 & 1 & 66.67 & Included \\
\hline Browne and Jenkins (2012) & 0 & 1 & 1 & 1 & 1 & 1 & 83.33 & Included \\
Coccia et al. (2012) & 0 & 1 & 1 & 0 & 1 & 1 & 66.67 & Included \\
Kwon and Wickrama (2014) & 0 & 1 & 1 & 1 & 1 & 1 & 83.33 & Included \\
Lohaus, Vierhaus, and Ball (2009) & 1 & 0 & 1 & 0 & 1 & 1 & 66.67 & Included \\
Nicholls et al. (2014) & 1 & 1 & 1 & 1 & 1 & 1 & 100 & Included \\
Philips et al. (2014) & 1 & 1 & 1 & 0 & 1 & 1 & 83.33 & Included \\
Ray and Roos (2012) & 1 & 1 & 1 & 0 & 1 & 1 & 83.33 & Included \\
Ray et al. (2013) & 0 & 1 & 1 & 1 & 1 & 1 & 83.33 & Included \\
Rew et al. (2013) & 1 & 1 & 1 & 1 & 1 & 1 & 100 & Included \\
Wong (2006) & & 1 & & & & &
\end{tabular}




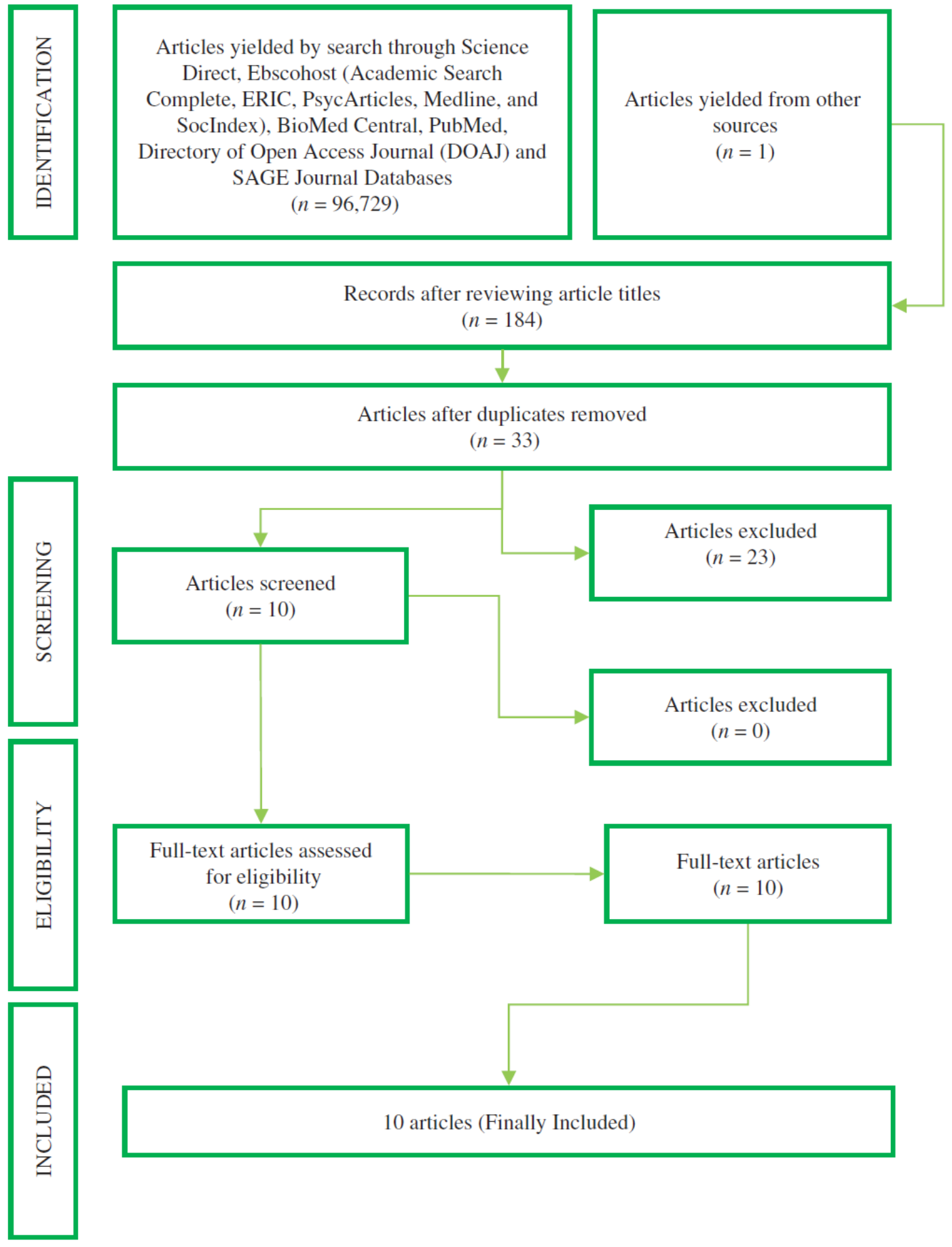

Figure 1. Diagrammatical representation of systematic review process.

\section{Results}

The studies that were considered for inclusion in the methodological quality appraisal phase of the systematic review can be found in Table 3. Of the thirty-three studies that were initially retrieved, ten studies met the criteria for methodological appraisal. 


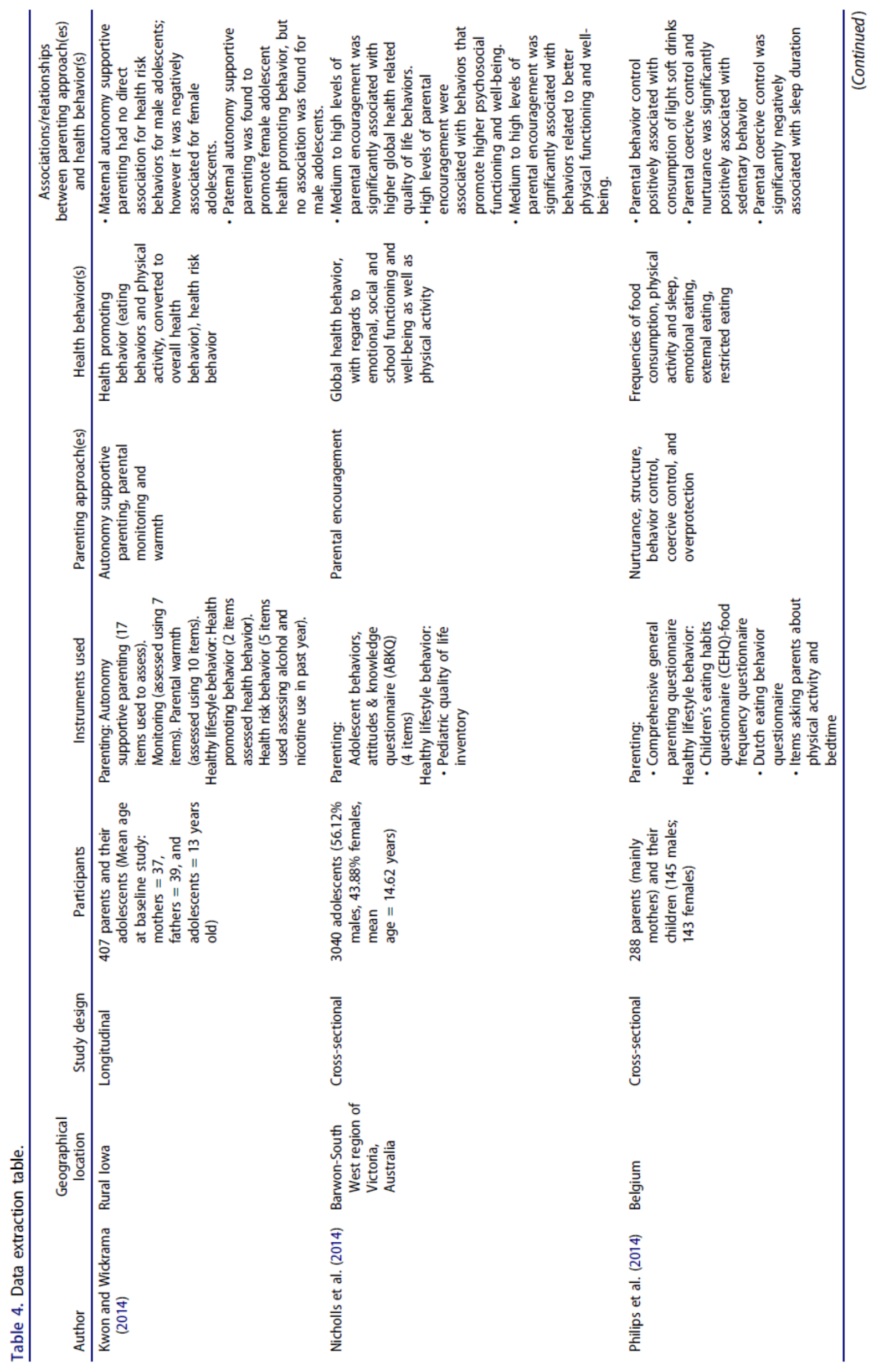




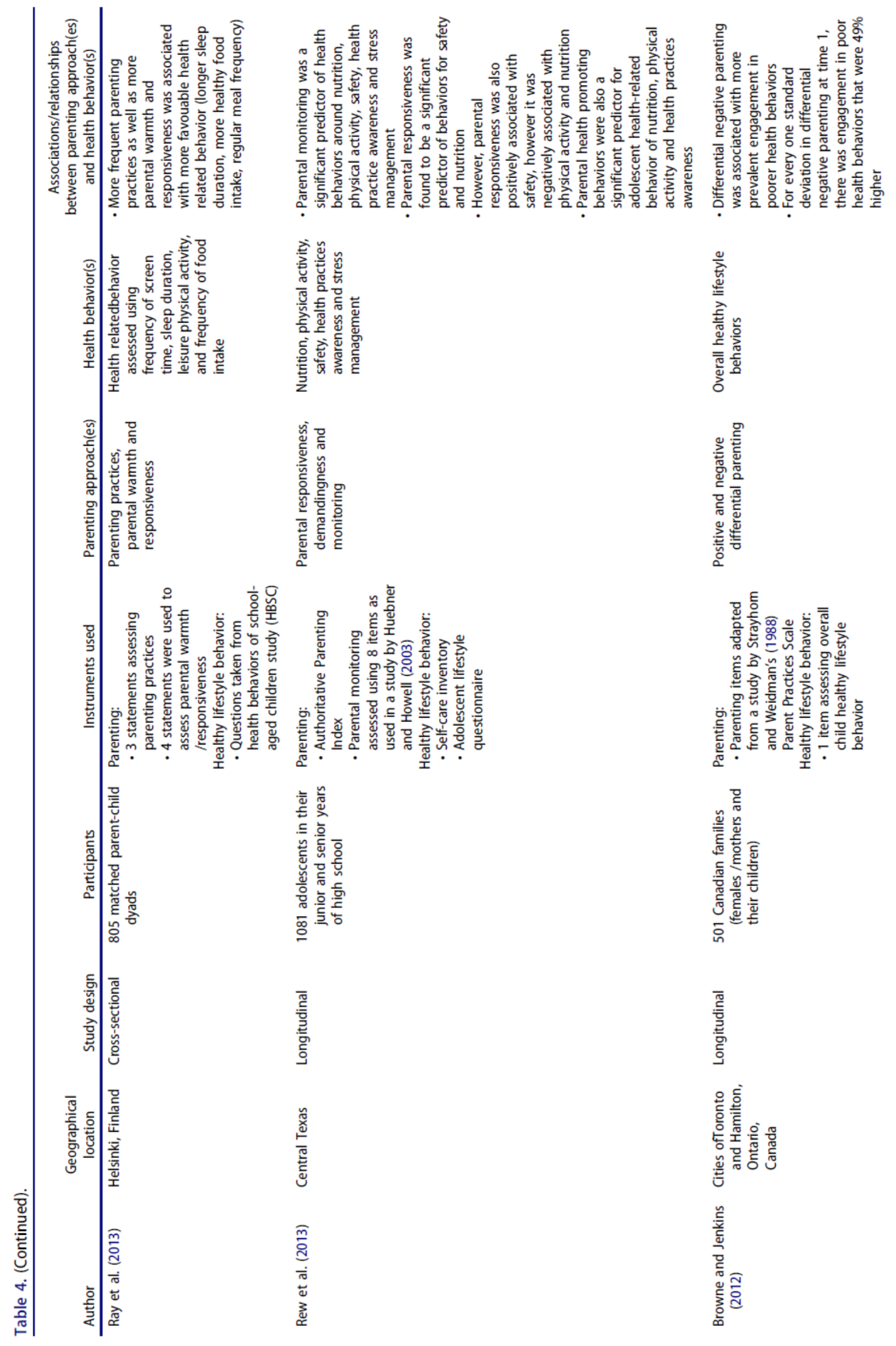




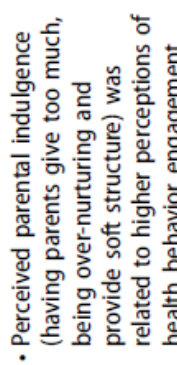
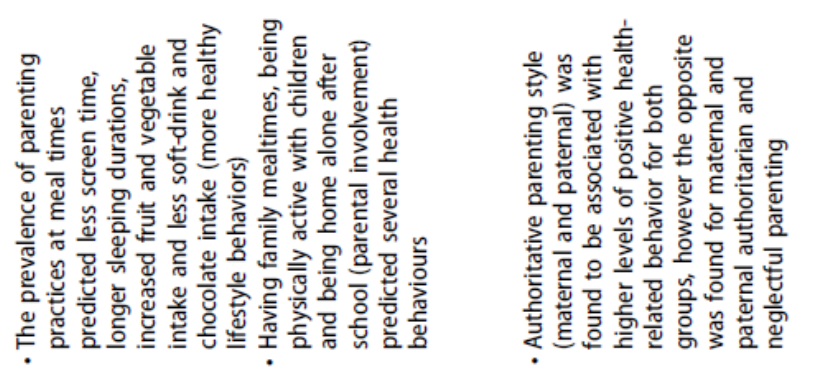

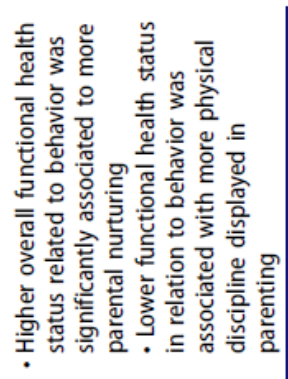

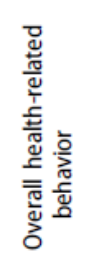
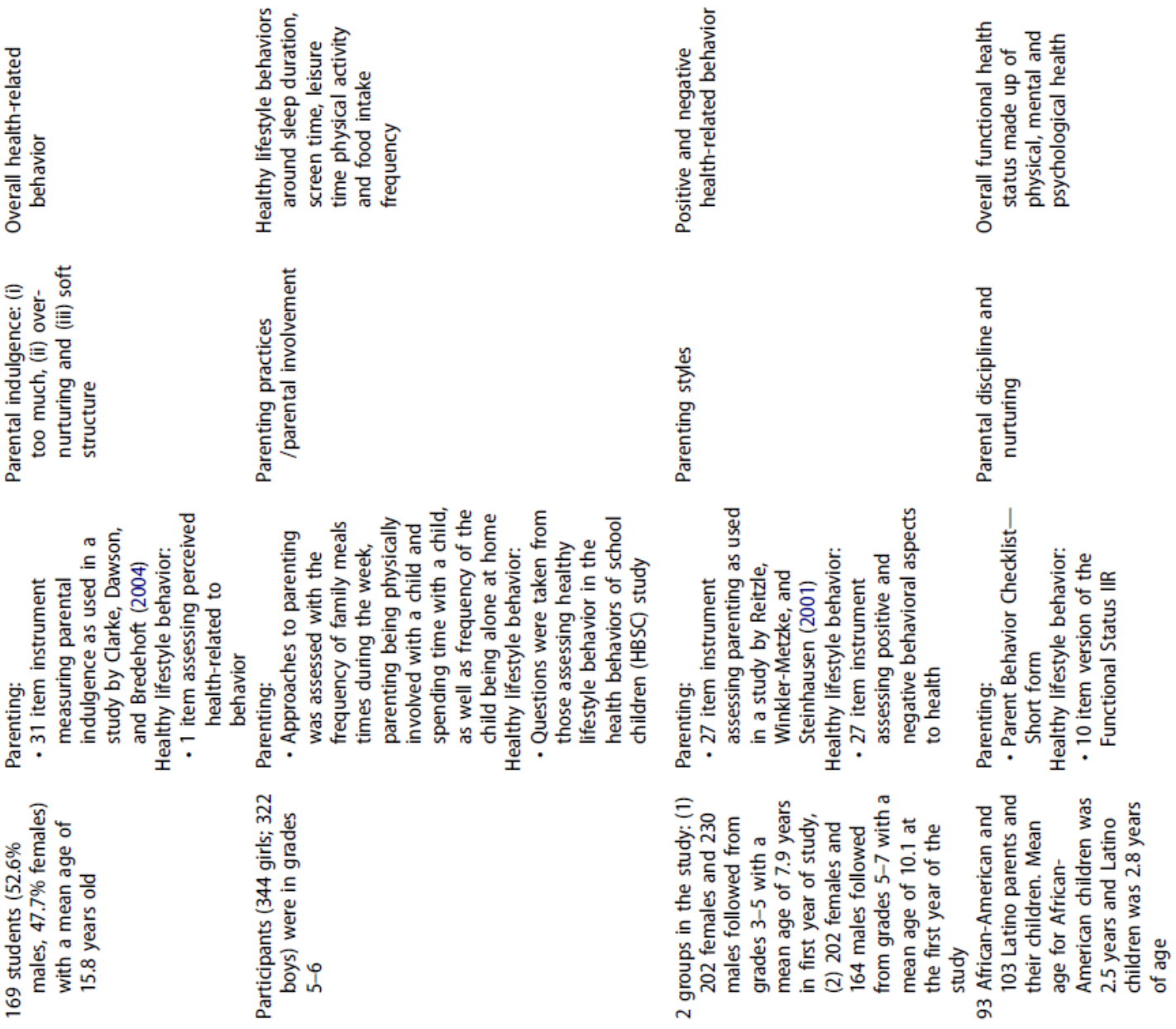

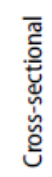

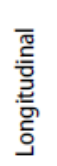

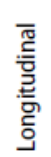

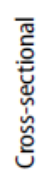

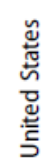

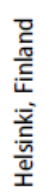

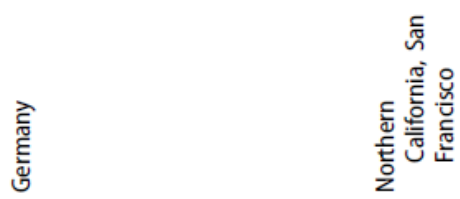

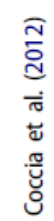

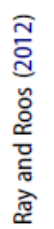

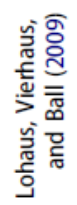

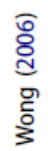


Table 5. Examining health behaviors, and associations with parenting approaches.

\begin{tabular}{|c|c|c|c|}
\hline Healthy lifestyle behaviors & Health behavior(s) & Author(s) & Association with parenting approach \\
\hline \multirow[t]{18}{*}{$\begin{array}{l}\text { Healthy lifestyle behaviors: } \\
\text { These are behaviors that } \\
\text { promote positive health and } \\
\text { well-being }\end{array}$} & General/overall health & $\begin{array}{l}\text { Kwon and Wickrama } \\
\text { (2014) }\end{array}$ & $\begin{array}{l}\text { - Paternal autonomy supportive parenting } \\
\text { positively associated with female health } \\
\text { promoting behavior, no association for } \\
\text { males. (+PA) }\end{array}$ \\
\hline & & Nicholls et al. (2014) & $\begin{array}{l}\text { - Medium to high levels of parental } \\
\text { encouragement positively associated (+PA) }\end{array}$ \\
\hline & & Ray et al. (2013) & $\begin{array}{l}\text { - Frequent parenting practices positively } \\
\text { associated (+PA) } \\
\text { - Parental warmth and responsiveness } \\
\text { positively associated (+PA) }\end{array}$ \\
\hline & & Rew et al. (2013) & $\begin{array}{l}\text { - Parental monitoring was a significant } \\
\text { predictor (+PA) } \\
\text { - Parental health promoting behaviors was a } \\
\text { predictor of health-related behaviors of } \\
(+P A)\end{array}$ \\
\hline & & $\begin{array}{l}\text { Browne and Jenkins } \\
\text { (2012) }\end{array}$ & $\begin{array}{l}\text { - Differential negative parenting negatively } \\
\text { associated (-PA) }\end{array}$ \\
\hline & & Coccia et al. (2012) & $\begin{array}{l}\text { - Perceived parental indulgence was } \\
\text { positively associated (-PA) }\end{array}$ \\
\hline & & $\begin{array}{l}\text { Lohaus, Vierhaus, and } \\
\text { Ball (2009) }\end{array}$ & $\begin{array}{l}\text { - Paternal and maternal authoritative } \\
\text { parenting was positively associated (+PA) } \\
\text { - Paternal and maternal authoritarian and } \\
\text { neglectful parenting was negatively } \\
\text { associated (-PA) }\end{array}$ \\
\hline & & Wong (2006) & $\begin{array}{l}\text { - Parental nurturing positively associated } \\
\text { with higher overall functional health status } \\
\text { (+PA) } \\
\text { - Physical discipline displayed by parent } \\
\text { negatively associated with overall functional } \\
\text { health status (-PA) }\end{array}$ \\
\hline & Nutrition & Philips et al. (2014) & $\begin{array}{l}\text { - Parental behavior control positively } \\
\text { associated (-PA) }\end{array}$ \\
\hline & & Rew et al. (2013) & $\begin{array}{l}\text { - Parental responsiveness negatively } \\
\text { associated and was a predictor for (+PA) }\end{array}$ \\
\hline & & Ray and Roos (2012) & $\begin{array}{l}\text { - Parenting practices (involvement) was } \\
\text { positively associated (+PA) }\end{array}$ \\
\hline & $\begin{array}{l}\text { Physical functioning } \\
\text { /physical activity }\end{array}$ & Nicholls et al. (2014) & $\begin{array}{l}\text { - Medium to high levels of parental } \\
\text { encouragement positively associated (+PA) }\end{array}$ \\
\hline & & Rew et al. (2013) & $\begin{array}{l}\text { - Parental responsiveness negatively } \\
\text { associated (+PA) }\end{array}$ \\
\hline & Sleep duration /quality & Philips et al. (2014) & $\begin{array}{l}\text { - Parental coercive control negatively } \\
\text { associated (-PA) }\end{array}$ \\
\hline & & Ray and Roos (2012) & $\begin{array}{l}\text { - Parenting practices (involvement) was } \\
\text { positively associated (+PA) }\end{array}$ \\
\hline & $\begin{array}{l}\text { Psychosocial } \\
\text { functioning }\end{array}$ & Nicholls et al. (2014) & $\begin{array}{l}\text { - Higher levels of parental encouragement } \\
\text { positively associated (+PA) }\end{array}$ \\
\hline & Screen-time & Ray and Roos (2012) & $\begin{array}{l}\text { - Parenting practices (involvement) was } \\
\text { positively associated (+PA) }\end{array}$ \\
\hline & Safety & Rew et al. (2013) & $\begin{array}{l}\text { - Parental responsiveness positively } \\
\text { associated as well as a predictor of (+PA) }\end{array}$ \\
\hline
\end{tabular}

Note: $+\mathrm{PA}=$ Positive Parenting Approach; $-\mathrm{PA}=$ Negative Parenting Approach.

The criteria that had to be satisfied as part of the methodological quality appraisal phase included sampling methods, measurement tools, data sources used, whether healthy lifestyle behaviors were considered, and whether the relationship between healthy lifestyle behaviors and parenting approaches were examined. Of the ten studies that formed part of the methodological quality appraisal, all scored good (67-100\%) for the methodological appraisal score. The sample for the review was made up of ten studies that met the criteria for inclusion during the methodological quality appraisal. 


\begin{tabular}{l}
\hline Parenting approach \\
\hline Positive parenting approach \\
Positive parenting approaches are \\
often synonymous with socially \\
acceptable developmental \\
outcomes for children and \\
adolescents (Davids \& Roman, \\
2014), and there is often a display \\
of nurturance, support, and \\
monitoring within the parent- \\
child relationship (Lee, Daniels, \& \\
Kissinger, 2006).
\end{tabular}

Nicholls et al. (2014)

Ray et al. (2013)

Rew et al. (2013)

Browne and Jenkins (2012) Positive differential parenting: The level of positivity experienced by the child within the parent-child relationship which has been associated with psychosocial and behavioral development (Browne \& Jenkins, 2012).

Ray and Roos (2012) • Parenting practices [parental involvement]: These practices refer to the behavioral strategies that parents employ where there is the display of involvement and parental warmth in the socialization and rearing of their children with the aim of promoting pro-social development (Ray et al., 2013).

Lohaus, Vierhaus, and Ball - Authoritative parenting style: Parenting where there is the

Negative parenting approach

Negative parenting approaches are synonymous with developmental outcomes which hinder positive, psychosocial development as a result of the parent-child relationship within children and adolescents (Betts, Trueman, Chiverton, Stanbridge, \& Stephens, 2013). It also involves parenting that occurs in the presence of inadequate Rew et al. (2013) parental monitoring and supervision, as well as a display of parental inconsistency and /or harsh forms of discipline (Barry, Frick, \& Grafeman, 2008). (2009)

Philips et al. (2014) display of high levels of both parental responsiveness and demandingness (Lohaus, Vierhaus \& Ball, 2009).

- Parental behavior control: The display of parental supervision in the child's daily activities (Philips et al., 2014).

- Coercive control: Parenting where there is the display of behaviors or actions that are intrusive and dominating where individuality and autonomy is discouraged (Philips et al., 2014).

- Parental over-protection: Excessive nurturing and strict control is common with the parent-child relationship (Philips et al., 2014).

- Parental demandingness: Parenting that is commonly associated with high levels of control.

Browne and Jenkins (2012) - Negative differential parenting: The level of negativity experienced by the child within the parent-child relationship which has been associated with negative outcomes on the psychosocial and emotional development of children (Browne \& Jenkins, 2012).

Coccia et al. (2012)

- Parental indulgence: Parenting where there is the display of over indulgence which has implications on the development of self-efficacy in the child (Coccia et al., 2012). 


\begin{tabular}{|c|c|c|}
\hline Parenting approach & Author(s) & Parenting approach definition \\
\hline & $\begin{array}{l}\text { Lohaus, Vierhaus, and Ball } \\
\text { (2009) }\end{array}$ & $\begin{array}{l}\text { - Authoritarian parenting: Parenting where there is a display } \\
\text { of high levels of demandingness and low levels of } \\
\text { responsiveness, which has been associated with } \\
\text { diminished outcomes for children (Lohaus, Vierhaus \& Ball, } \\
2009 \text { ). } \\
\text { - Neglectful parenting: Parenting that is commonly } \\
\text { associated with low displays of demandingness and } \\
\text { responsiveness in the parent-child relationship (Lohaus, } \\
\text { Vierhaus \& Ball, 2009). }\end{array}$ \\
\hline & Wong (2006) & $\begin{array}{l}\text { - Physical parent discipline: Parenting where there is the } \\
\text { display of physical forms of parenting. }\end{array}$ \\
\hline
\end{tabular}

\section{Overview of the reviewed studies}

The systematic review sample consisted of 10 studies, of which five were cross-sectional (Coccia, Darling, Rehm, Cui, \& Sathe, 2012; Nicholls et al., 2014; Philips, Sioen, Michels, Sleddens, \& De Henauw, 2014; Ray, Kalland, Lehto, \& Roos, 2013; Wong, 2006) and five longitudinal (Browne \& Jenkins, 2012; Kwon \& Wickrama, 2014; Lohaus, Vierhaus \& Ball, 2009; Ray \& Roos, 2012; Rew, Arheart, Thompson, \& Johnson, 2013). From a geographical perspective, five studies were conducted in North America (Browne \& Jenkins, 2012; Coccia et al., 2012; Kwon \& Wickrama, 2014; Rew et al., 2013; Wong, 2006), four in Europe (Lohaus, Vierhaus, \& Ball, 2009; Philips et al., 2014; Ray et al., 2013; Ray \& Roos, 2012), and one in Australia (Nicholls et al., 2014). No studies included in the review were from Africa, Asia, and South America. The studies reported the ages of the children and adolescents to be within the range from 3 to 16 years of age. Some of the studies also reported data collected from parent-child dyads.

\section{Health behavior}

Health behaviors have been defined as the behaviors that individuals engage in that form part of one's daily routines; these include diet, physical activity, sedentary behaviors, and sleep (Ray \& Roos, 2012). However, often when examining health behavior, physical activity and nutritional behaviors are often thought of. When considering the World Health Organization's definition of health, this too speaks of a holistic understanding of health that extends beyond merely engaging in physical activity and nutri- tional dietary behaviors. In the review, a number of health behaviors that promote health and well-being were examined (Table 5). These health behaviors included: overall or general health behavior (Browne \& Jenkins, 2012; Coccia et al., 2012; Kwon \& Wickrama, 2014; Lohaus, Vierhaus, \& Ball, 2009; Nicholls et al., 2014; Ray et al., 2013; Rew et al., 2013; Wong, 2006), nutritional behavior (Philips et al., 2014; Ray \& Roos, 2012; Rew et al., 2013), physical activity and functioning (Nicholls et al., 2014; Rew et al., 2013), sleep duration (Philips et al., 2014; Ray \& Roos, 2012), psychosocial functioning and well-being (Nicholls et al., 2014), screen-time behaviors (Ray \& Roos, 2012), and safety (Rew et al., 2013). Of these health-related behaviors, the most prevalent was overall or general health behavior. The health- related behavior of overall or general health behavior was made up of a number of health-related behaviors within the various studies. These health behaviors included nutritional dietary behaviors, physical activity, frequency of health-risk behaviors, emotional and social functioning, overall physical, mental and psychological health, and overall healthy lifestyle-related behaviors (Browne \& Jenkins, 2012; Coccia et al., 2012; Kwon \& Wickrama, 2014; Lohaus, Vierhaus, \& Ball, 2009; Nicholls et al., 2014; Ray et al., 
2013; Rew et al., 2013; Wong, 2006). The health behaviors with the least prevalence in the review included: psychosocial functioning and well-being (Nicholls et al., 2014), screentime behaviors (Ray \& Roos, 2012) and safety (Rew et al., 2013).

\section{Parenting approaches}

The myriad of parenting approaches examined within the various studies in the review highlights the complexity of parenting (Table 4). The parenting approaches identified within the various studies were categorized into being either positive or negative parenting approaches based on the definition of the approaches used within the studies examined (Table 6), and this is similar to a review conducted by Davids, Roman, and Leach (2015) that categorized parenting approaches into positive and negative forms of parenting. Nineteen parenting approaches were identified in the 10 studies reviewed; the positive parenting approach was the most prevalent parenting approach in the reviewed studies (Browne \& Jenkins, 2012; Kwon \& Wickrama, 2014; Lohaus, Vierhaus, \& Ball, 2009; Nicholls et al., 2014; Philips et al., 2014; Ray et al., 2013; Ray \& Roos, 2012; Rew et al., 2013; Wong, 2006), and negative parenting was the least prevalent (Browne \& Jenkins, 2012; Coccia et al., 2012; Lohaus, Vierhaus, \& Ball, 2009; Philips et al., 2014; Rew et al., 2013; Wong, 2006). The studies by Philips et al. (2014), Rew et al. (2013), Browne and Jenkins (2012), Lohaus, Vierhaus and Ball (2009) and Wong (2006) included both positive and negative parenting approaches.

Based on the parenting approaches presented in Table 4 and considering the definitions of the approaches, ten parenting approaches were categorized as positive parenting approaches, namely: (1) autonomy supportive parenting (Kwon \& Wickrama, 2014), (2) parental monitoring and warmth (Kwon \& Wickrama, 2014), (3) parental encouragement (Nicholls et al., 2014), (4) parental nurturance (Philips et al., 2014; Wong, 2006), (5) parental structure (Philips et al., 2014), (6) positive parenting practices (Ray et al., 2013), (7) parental warmth and responsiveness (Ray et al., 2013; Rew et al., 2013), (8) positive differential parenting (Browne \& Jenkins, 2012), (9) parental involvement (Ray \& Roos, 2012), and (10) authoritative parenting (Lohaus, Vierhaus, \& Ball, 2009). Nine approaches presented in the review were categorized as being negative parenting approaches, namely: (1) parental behavior control (Philips et al., 2014), (2) coercive control (Philips et al., 2014), (3) parental over-protection (Philips et al., 2014), (4) parental demandingness (Rew et al., 2013), (5) negative differential parenting (Browne \& Jenkins, 2012), (6) parental indulgence (Coccia et al., 2012), (7) authoritarian parenting (Lohaus, Vierhaus, \& Ball, 2009), (8) neglectful parenting (Lohaus, Vierhaus, \& Ball, 2009), and physical parent discipline (Wong, 2006).

\section{Associations between health behavior and parenting approaches}

The data extracted from the included studies in the review found specific parental approaches to be associated with behaviors that promote positive health and development (Tables 4 and 5). Parental autonomy supportive parenting (Kwon \& Wickrama, 2014), parental encouragement (Nicholls et al., 2014), parental behaviour control (Philips et al., 2014), warmth and responsiveness (Ray et al., 2013; Rew et al., 2013), parental monitoring (Rew et al., 2013), parental health promoting behaviours (Rew et al., 2013), authoritative parenting (Lohaus, Vierhaus, \& Ball, 2009), and parental 
nurturance (Wong, 2006) were all associated with health behaviors that promote health (Table 5). The behaviors that were associated with these parenting approaches included behaviors that promote overall health status, nutritional and dietary behaviors, physical activity and functioning, sleep behaviors related to duration and quality, psychosocial functioning, screen-time behaviors, and safety (Browne \& Jenkins, 2012; Coccia et al., 2012; Kwon \& Wickrama, 2014; Lohaus, Vierhaus, \& Ball, 2009; Nicholls et al., 2014; Philips et al., 2014; Ray et al., 2013; Ray \& Roos, 2012; Rew et al., 2013; Wong, 2006).

The parenting approaches that were associated with health behaviors which promoted health less were coercive control and over-protection (Philips et al., 2014), parental demandingness (Rew et al., 2013) and physical discipline (Wong, 2006), negative differential parenting (Browne \& Jenkins, 2012), indulgent (Coccia et al., 2012), neglectful, and authoritarian parenting (Lohaus, Vierhaus, \& Ball, 2009) (Tables 4 and $5)$.

The associations between parenting approaches and health behavior found (1) gender differences in males and females, where more significant associations were found for females than for males (Kwon \& Wickrama, 2014), (2) parents who engaged in health behaviors that promote health was a significant predictor for adolescent health behavior and their health responsibility (Rew et al., 2013) (Table 4).

The results presented in Table 4 suggests that the construct of health behaviors is very heterogeneous and is associated with parenting approaches which are both positive and negative in nature. Even though health behavior is presented homogeneously in the associations with parenting approaches, an understanding of the overarching concept of health behaviors is presented in Table 5 highlighting that health behavior is heterogeneous in the review. These included behaviors that promote the overall health status of children and adolescents as well as behaviors around safety that influences health (Table 5).

\section{Discussion}

The developmental phase of adolescence often is associated with engaging in behaviors that could either promote positive health or hinder it. The behaviors that are established during this develop- mental phase have been associated with outcomes in later life. However, central to the establishment of health-related behaviors has been the influential role of the parent-child relationship. The current review aimed to establish the associations between health behavior of children and adolescents and parenting approaches.

\section{Health behavior}

Health-related behaviors are influenced by a number of factors which could be behavioral, psychsocial, or sociocultural in nature (Terre, 2007). Often when considering the behaviors related to the health status of individual's, behaviors related to nutrition and physical activity are thought of. However, when considering the factors related to health behavior, as suggested by Terre (2007), considering dietary behaviors and physical activity in isolation to the promotion of positive health and well-being would be limiting. Lifestylerelated behavior that promotes positive health should consider behaviors related to both 
psychosocial and sociocultural dimensions of an individual's life to aid in the promotion of positive health and the prevention of ill-health (Sleet, Gielen, Diekman, \& Ikeda, 2010). This too is presented in the World Health Organization (WHO, 2006)'s definition of health as being "a state of complete physical, mental and social well-being and not merely the absence of disease or infirmity." The current review therefore considered health behavior that included the physical, mental and social health and well-being of children and adolescents. The most prevalent health behavior presented in the review was behaviors that were in the category of overall and/or general health behavior. These behaviors ranged from physical, mental and psychological health behaviors which were representative of the health behaviors as considered in the WHO (2006)'s definition of health. Health behaviors have been presented within literature to be associated with a number of positive developmental outcomes on health and well-being, these include: decreased prevalence and incidence of diseases such as cardiovascular disease and cancer (Grunbaum, Lowry, \& Kann, 2001) and a decline in death rates related to ill-health (Wang, Ou, Chen, \& Duan, 2009) as well as immediate and long term positive health and wellbeing outcomes (Pender, Murdaugh, \& Parsons, 2010), self-efficacy (Smith, 2011; Smith \& Holloman, 2013), increased sense of psychological safety (Harris, 1998), heightened self-esteem and healthier self-concept (Taylor \& Turner, 2001), decreased risk of obesity and being overweight (Garaulet et al., 2011), and increase energy levels (Gaina et al., 2007). On the contrary, literature suggests that health-risk behaviors are often associated with engagement in substance abuse, sexual risk taking behavior, adoption of poor diet and physical inactivity, diminished mental health and engagement in violence which hinders the development of children and adolescents (Johnson \& Taliaferro, 2012; Wang et al., 2009). Interestingly, the health behaviors that children and adolescents engage in are often as a result of the contributory role that the environment plays (Johnson \& Taliaferro, 2012). The environment that children and adolescents are often exposed to is their familial home environment in which parenting takes place.

\section{The role of parenting}

Parenting as a central element of the familial home environment is often thought of as being a process. Parenting as a process is largely concerned with the direct and indirect interactions between child and parent and how it plays a role in the pro-social development of children and adolescents (Brooks, 2011). The impact that parenting has on the parent-child relationship has been of interest, particularly with regard to the development of the child and adolescent. The process of parenting could be seen as one that promotes pro-social behaviors, development and well-being (positive parenting approaches) (Davids et al., 2015; Kaiser, McBurnett, \& Pfiffner, 2011) or it could hinder the prosocial development and create a diminished sense of well-being (negative parenting approaches) (Dallaire et al., 2006). The role that these parenting approaches exert on the develop- ment of children and adolescents can be seen as having a ripple effect on development throughout the lifespan of individuals, as can be found in literature. In the review, the parenting approaches were categorized into positive and negative parenting approaches. The most prevalent parenting approach presented within the review was the positive parenting approach.

\section{http://repository.uwc.ac.za}




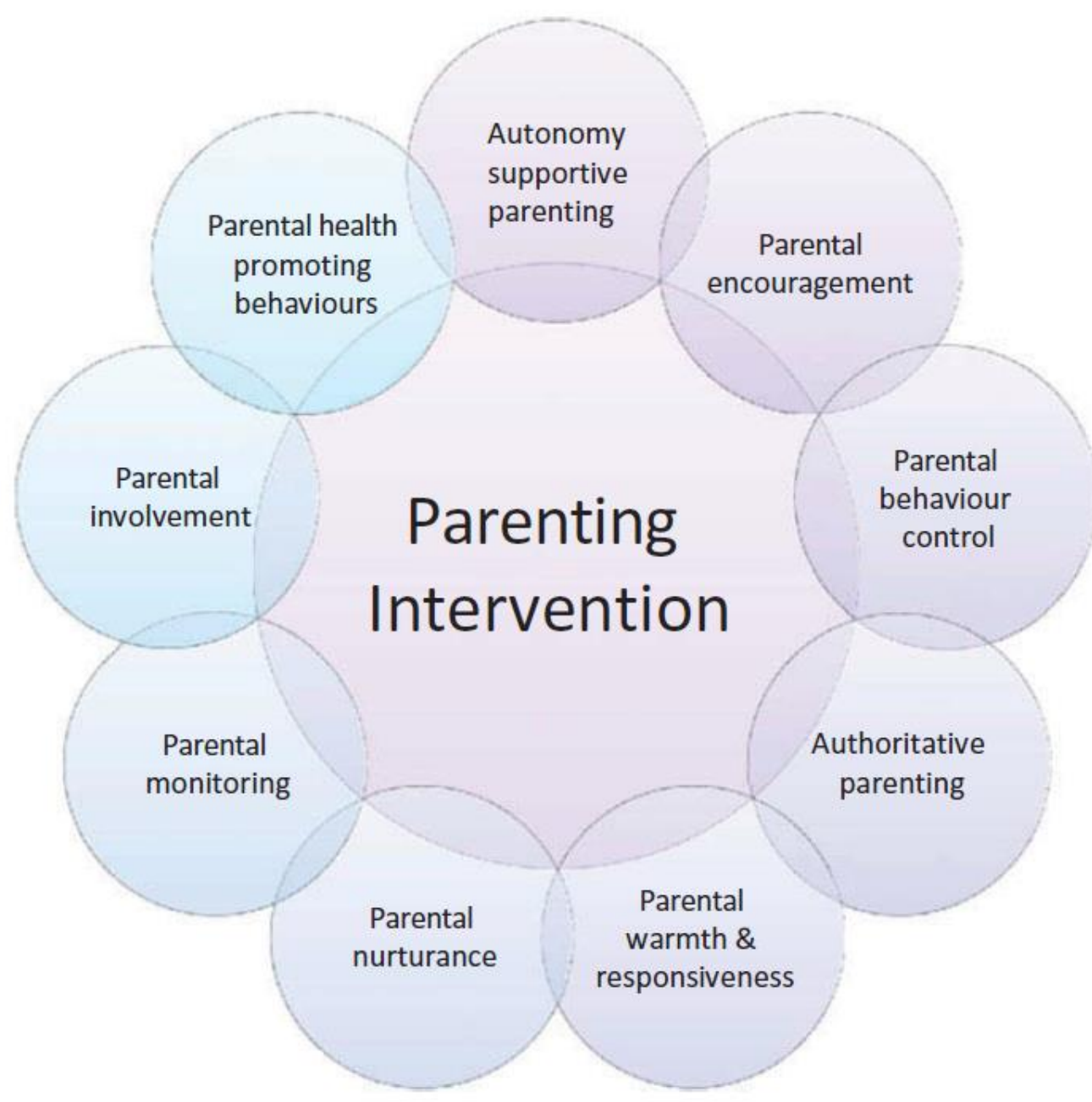

Figure 2. Parenting approaches to inform parenting interventions to improve child and adolescent health.

The positive parenting approach has been associated with a number of positive developmental outcomes and socially appropriate behaviors for children and adolescents (Danzig, Dyson, Olino, Laptook, \& Klein, 2015). Developmentally children who were raised by parents who display positive parenting approaches were found to be well-adjusted (Danzig et al., 2015), display diminished behavioral problems (Aunola \& Nurmi, 2005) and are socially competent (Baumrind, 1991), while negative parenting approaches have been associated with developmental outcomes that have implications on the development of the child and adolescent.

\section{The link: Health behavior and parenting approaches}

For centuries, parenting approaches have been associated with a number of developmental outcomes for children and adolescents alike (Davids \& Roman, 2014; Davids et al., 2015). Parenting approaches that allow for autonomy and display warmth have been associated with a number of positive developmental outcomes (Aunola \& Nurmi, 2005). The results presented in the review suggest that autonomy supportive parenting, parental encouragement, behavior control, authoritative parenting, parental warmth and responsiveness, parental nurturance and monitoring, and parental involvement are the parenting approaches that have been associated with health behaviors that promote positive health in children and adolescents. The results suggest that when parents make use of these approaches, their children and adolescents are more likely to be associated with an increase in healthy lifestyle behavior. These associations of between parenting approaches 
and health behavior as presented in the review adds to our understanding of healthparticularly among children and adolescents. Understanding health of adolescents has been ignored within studies for a long time and has generated gaps in our understanding of the health of young people (Patton et al., 2016). The associations between parenting approaches and health behavior, as examined within the review, also afford the opportunity to make use of evidence-based decision-making in interventions that are aimed at promoting positive health and development of children and adolescents. Interventions focused on parenting to promote health behavior should take into consideration the parenting approaches associated with positive health behavior (See Figure 2). The parental home environment plays an important role in the development and maintenance of health-related behaviors. By informing parenting interventions aimed at promoting child and adolescent health behavior, the parenting approaches as defined in Figure 2 could be incorporated into interventions as supported by evidence-based practice.

The findings presented contribute to current public health concerns about noncommunicable and other lifestyle-related diseases (Proimos \& Klein, 2012; Tagoe \& Dake, 2011). Non-communicable diseases are often associated with lifestyle-related behaviors that diminish positive health and well-being and has posed an international concern with the ever increasing numbers (Hanson \& Gluckman, 2015). Kwon and Wickrama (2014) have alluded to the important role that the familial home environment, where parenting often takes place, plays in either the promotion or hindering of healthy lifestyle behaviors. The results presented in the review confirm the important role of parenting in health behaviors (Kwon \& Wickrama, 2014) as parenting approaches (highlighted in Figure 2) have been associated with health behaviors in children and adolescents. The current review suggests that the important role that parenting plays in the adoption and maintenance of health behaviors could promote positive health and might lessen the burden of non-communicable diseases as a public health concern highlighted by the United Nations.

\section{Implications for practice}

The findings presented in the review highlights the role that parenting approaches play in the associations with health behavior of children and adolescents. Globally, noncommunicable disease poses as a public health concern and innovative strategies are needed to tackle this concern. Public health practitioners and policy makers could use the findings of the current review to develop and implement parenting programs that promote the parenting approaches as determined within the review (namely, autonomy supportive parenting (Kwon \& Wickrama, 2014), parental monitoring and warmth (Kwon \& Wickrama, 2014), parental encouragement (Nicholls et al., 2014), parental nurturance (Philips et al., 2014; Wong, 2006), parental structure (Philips et al., 2014), positive parenting practices (Ray et al., 2013), parental warmth and responsiveness (Ray et al., 2013; Rew et al., 2013), positive differential parenting (Browne \& Jenkins, 2012), parental involvement (Ray \& Roos, 2012), and authoritative parenting (Lohaus, Vierhaus, \& Ball, 2009); see Figure 2) to assist in the promotion of health behaviors which could assist in lessening the current burden of mortality and morbidity as a result of the steep incline in non-communicable and other lifestyle-related diseases. 


\section{Limitations and recommendations}

One of the limitations of the current review was the lack of focus on socioeconomic status when examining the associations between health behavior of children and adolescents and parenting approaches. Socioeconomic inequalities play an important role in the health status and behaviors of societies (Rathmann et al., 2015) therefore to examine the effect of socioeconomic status in the associations between health behavior and parenting approaches would yield even greater outcomes for program development and implementation to address some of the emerging public health concerns, such as non-communicable diseases. Socioeconomic status has been documented as playing a pivotal role in the associations with child and adolescent health (Hanson \& Chen, 2007). Additionally, as we acknowledge the important role that parenting plays in health behavior, the role that decision-making plays in health behavior should not be excluded. In order to address current public health concerns associated with lifestylerelated diseases, understanding the decision-making process that children and adolescents engage in before arriving at a particular health behavior should be considered in future studies.

The review has considered health behavior as a homogeneous construct which presents limitations methodologically within the review. Health behaviors are complex and vary from one another substantially. In allowing for a more heterogeneous understanding of health behavior and its associations with parenting approaches future studies should consider specific health behaviors, such as physical activity, eating habits, and screen-time behaviors rather than using a broad and overarching construct such as health behaviors which may present limitations in both the search strategy and extraction of studies.

Additionally, another limitation that has emerged within the review related to the understanding of the role of parental approaches has been the lack of considering the differential role that maternal and paternal caregivers play in the associations related to healthy lifestyle behaviors. Inconsistency in maternal and paternal parenting approaches has been identified (Rinaldi \& Howe, 2012), and therefore, a recommendation for future research would be to consider the differential role that maternal and paternal parenting could play in the associations presented within the review. Furthermore, the role of paternal parenting too has changed as a result of social and historical changes in terms of paternal involvement in parent-child interactions (Cabrera, Tamis-LeMonda, Bradley, Hofferth, \& Lamb, 2000).

Future research should also consider the role that society plays in the conceptions of positive and negative parenting, as what is considered negative parenting in Western societies are considered positive in other societies. This difference in societal conceptions of parenting can be seen in authoritarian parenting that is considered detrimental to child development in Western societies but in Asian societies, the opposite is found (Ang \& Goh, 2006; Chao, 2001).

\section{Conclusion}

Parenting has played an important role in the development of children and adolescents. The review identified parenting approaches associated with health behaviors of children and 
adolescents. The findings presented, in the review, might aid recommendations for program development and implementation particularly in addressing some of the lifestylerelated diseases that pose a threat to children and adolescents.

\section{Funding}

The financial assistance of the National Research Foundation (NRF) toward this research is hereby acknowledged. Opinions expressed and conclusions arrived at are those of the authors and are not necessarily to be attributed to the NRF.

\section{ORCID}

Eugene Lee Davids http://orcid.org/0000-0002-3805-3904 


\section{References}

Ang, R. P., \& Goh, D. H. (2006). Authoritarian parenting style in Asian societies: A cluster-analytic investigation. Contemporary Family Therapy, 28(1), 131-151. doi:10.1007/s10591-006-9699-y

Aunola, K., \& Nurmi, J. (2005). The role of parenting styles in children's problem behaviour. Child Development, 76 (6), 1144-1159. doi:10.1111/j.14678624.2005.00840.x-i1

Barry, C. T., Frick, P. J., \& Grafeman, S. J. (2008). Child versus parent reports of parenting practices: Implications for the conceptualization of child behavioral and emotional problems. Assessment, 15(3), 294-303. doi:10.1177/1073191107312212

Baumrind, D. (1991). The influence of parenting style on adolescent competence and substance use. Journal of Early Adolescence, 11, 56-95. doi:10.1177/0272431691111004

Betts, L. R., Trueman, M., Chiverton, L., Stanbridge, A., \& Stephens, J. (2013). Parental rearing style as a predictor of attachment and psychosocial adjustment during young adulthood. Journal of Social and Personal Relationships, 30 (6), 675-693. doi:10.1177/0265407512465998

Brooks, J. B. (2011). The process of parenting. New York, NY: McGraw-Hill.

Browne, D. T., \& Jenkins, J. M. (2012). Health across early childhood and socio-economic status: Examining the moderating effects of differential parenting. Social Science \& Medicine, 74, 1622-1629. doi:10.1016/j.socscimed.2012.01.017

Bruhn, J. G. (1988). Lifestyle and health behaviour. In D. S. Gochman (Ed.), Health behaviour: Emerging research perspectives. New York, NY: Plenum Press.

Burusic, J., Sakic, M., \& Koprtla, N. (2014). Parental perceptions of adolescent health behaviours: Experiences from Croatian high schools. Health Education Journal, 73(3), 351-360. doi:10.1177/0017896912471522

Cabrera, N. J., Tamis-LeMonda, C. S., Bradley, R. H., Hofferth, S., \& Lamb, M. E. (2000). Fatherhood in the twenty first century. Child Development, 71, 127-136. doi:10.1111/cdev.2000.71.issue-1

Chao, R. K. (2001). Extending research on the consequences of parenting style for Chinese Americans and European Americans. Child Development, 72, 1832-1843. doi:10.1111/cdev.2001.72.issue-6

Clarke, J., Dawson, C., \& Bredehoft, D. (2004). How much is enough? Everything you need to know to steer clear of overindulgence and raise likable, responsible, and respectful children. New York, NY: Marlowe \& Company.

Coccia, C., Darling, C. A., Rehm, M., Cui, M., \& Sathe, S. K. (2012). Adolescent health, stress and life satisfaction: The paradox of indulgent parenting. Stress \& Health, 28, 211-221. doi:10.1002/smi.v28.3

Cohen, D. A., Scribner, R. A., \& Farley, T. A. (2000). A structural model of health behaviour: A pragmatic approach to explain and influence health behaviours at the population level. Preventive Medicine, 30, 146-154. doi:10.1006/pmed.1999.0609

Dallaire, D. H., Pineda, A. Q., Cole, D. A., Ciesla, J. A., Jacquez, F., LaGrange, B., \& Bruce, A. E. (2006). Relation of positive and negative parenting to children's depressive symptoms. Journal of Clinical Child and Adolescent Psychology, 35(2), 313-322. doi:10.1207/s15374424jccp3502_15

Danzig, A. P., Dyson, M. W., Olino, T. M., Laptook, R. S., \& Klein, D. N. (2015). Positive parenting interacts with child temperament and negative parenting to predict 
children's socially appropriate behaviour. Journal of Social and Clinical Psychology, 34(5), 411-435. doi:10.1521/jscp.2015.34.5.411

Davids, E. L., \& Roman, N. V. (2014, October). A systematic review of the relationship between parenting styles and children's physical activity. African Journal for Physical, Health Education, Recreation and Dance, 20(Suppl. 2), 228-246.

Davids, E. L., Roman, N. V., \& Leach, L. (2015). Decision making styles: A systematic review of their associations with parenting. Adolescent Research Review, 1(1). doi:10.1007/s40894-015-0003-y

Gaina, A., Sekine, M., Hamanishi, S., Chen, X., Wang, H., Yamagami, T., \& Kagamimori, S. (2007). Daytime sleepiness and associated factors in Japanese school children. The Journal of Pediatrics, 151, e1-e4. doi:10.1016/j.jpeds.2007.04.036

Garaulet, M., Ortega, F. B., Ruiz, J. R., Rey-Lopez, J. P., Beghin, L., Manios, Y., . . . Moreno, L. A. (2011). Short sleep duration is associated with increase obesity markers in European adolescents: Effect of physical activity and dietary habits: The HELENA study. International Journal of Obesity, 35, 1308-1317. doi:10.1038/ijo.2011.149

Goldsteen, R. L., Goldsteen, K., \& Graham, D. G. (2011). Introduction to Public Health. New York, NY: Springer Publishing Company.

Gore, F. M., Bloom, P. J., Patton, G. C., Ferguson, J., Joseph, V., Coffey, C., ... Mathers, C. D. (2011). Global burden of disease in young people ages 10-24 years: A systematic analysis. Lancet, 377, 2093-2102. doi:10.1016/So140-6736 (11)605126

Grunbaum, J. A., Lowry, R., \& Kann, L. (2001). Prevalence of health-related behaviours among alternative high school students as compared with students attending regular high schools. Journal of Adolescent Health, 29, 337-343. doi:10.1016/S1054-139X(01)00304-4

Guise, V., Anderson, J., \& Wiig, S. (2014). Patient safety risks associated with telecare: A systematic review and narrative synthesis of the literature. $B M C$ Health Services Research, 14, 1-15. doi:10.1186/s12913-014-0588-z

Hanson, M. A., \& Gluckman, P. D. (2015). Developmental origins of health and disease: Global public health implications. Best Practice \& Research Clinical Obstetrics and Gynaecology, 29, 24-31. doi:10.1016/j. bpobgyn.2014.06.007

Hanson, M. D., \& Chen, E. (2007). Socioeconomic status and health behaviours in adolescence: A review of the literature. Journal of Behavioural Medicine, 30 , 263-285. doi:10.1007/s10865-007-9098-3

Harris, J. (1998). The Nurture Assumption. New York, NY: Academic Press.

Huebner, A. J., \& Howell, L. W. (2003). Examining the relationship between adolescent sexual risk-taking and perceptions of monitoring, communication, and parenting styles. Journal of Adolescent Health, 33, 71-78. doi:10.1016/S1054139X(03)00141-1

Johnson, K. E., \& Taliaferro, L. A. (2012). Health behaviours and mental health of students attending alternative high schools: A review of the research literature. Journal for Specialist in Paediatric Nursing, 17, 79-97. doi:10.1111/ j.17446155.2011.00311.x

Kaiser, N. M., McBurnett, K., \& Pfiffner, L. J. (2011). Child ADHD severity and positive and negative parenting as predictors of child social functioning: Evaluation of 
three theoretical models. Journal of Attention Disorders, 15(3), 193-203. doi:10.1177/1087054709356171

Kitamura, T., Uji, M., Chen, Z., Murakami, M., \& Goto, Y. (2014). Determinants of parenting styles of Japanese fathers and mothers with children aged o to 10: Perceived parenting during childhood or dysphoric mood. The Open Family Studies Journal, 6, 8-16.

Kwon, J. A., \& Wickrama, K. A. S. (2014). Linking family economic pressure and supportive parenting to adolescent health behaviour: Two developmental pathways leading to health promoting and health risk behaviour. Journal of Youth and Adolescence, 43, 1176-1190. doi:10.1007/s10964-013-0060-0

Le Boutillier, C., Chevalier, A., Lawrence, V., Leamy, M., Bird, V. J., Macpherson, R., ... Slade, M. (2015). Staff understanding of recovery-orientated mental health practice: A systematic review and narrative synthesis. Implementation Science, 1O, 1-14. doi:10.1186/s13012-015-0275-4

Leamy, M., Bird, V., Le Boutillier, C., Williams, J., \& Slade, M. (2011). Conceptual framework for personal recovery in mental health: Systematic review and narrative synthesis. British Journal of Psychiatry, 199, 445-452. doi:10.1192/ bjp.bp.110.083733

Leddy, S. K. (2003). Integrative health promotion: Conceptual bases for nursing practice. Thorofare, NJ: Slack.

Lee, S. M., Daniels, M. H., \& Kissinger, D. B. (2006). Parental influences on adolescent adjustment: Parenting styles versus parenting practices. The Family Journal, 14(3), 253-259. doi:10.1177/1066480706287654

Lohaus, A., Vierhaus, M., \& Ball, J. (2009). Parenting styles and health-related behaviour in childhood and early adolescence: Results of a longitudinal study. Journal of Early Adolescence, 29(4), 449-475. doi:10.1177/ 0272431608322954

Louw, Q. A., Morris, L. D., \& Grimmer-Somers, K. (2007). The prevalence of low back pain in Africa: A systematic review. BMC Musculoskeletal Disorders, 8, 105.

Mokdad, A. H., Forouzanfar, M. H., Daoud, F., Molded, A. A., El Bcheraoui, C., MoradiLakeh, M., .. Murray, C. J. L. (2016). Global burden of diseases, injuries, and risk factors for young people's health during 1990-2013: A systematic analysis for the global burden of disease study 2013. Lancet, 387, 2383-2401. doi:10.1016/So140-6736 (16)00648-6

Nagata, J. M., Ferguson, B. J., \& Ross, D. A. (2016). Research priorities for eight areas of adolescent health in low- and middle-income countries. Journal of Adolescent Health, 59, 50-60. doi:10.1016/j.jadohealth.2016.03.016

Nicholls, L., Lewis, A. J., Petersen, S., Swinburn, B., Moodie, M., \& Millar, L. (2014). Parental encouragement of healthy behaviours: Adolescent weight status and health-related quality of life. BMC Public Health, 14, 369-377. doi:10.1186/14712458-14-369

Patton, G. C., Sawyer, S. M., Santelli, J. S., Ross, D. A., Afifi, R., Allen, N. B., ... Viner, R. M. (2016). Our future: A Lancet commission on adolescent health and wellbeing. Lancet Commissions. doi:10.1016/So140-6736(16)00579-1 Pender, N. J., Murdaugh, C. L., \& Parsons, M. A. (2010). Health promotion in nursing practice. Upper Saddle River, NJ: New Jersey: Prentice Hall.

Philips, N., Sioen, I., Michels, N., Sleddens, E., \& De Henauw, S. (2014). The influence of parenting style on health related behaviour of children: Findings from the 
ChiBS study. International Journal of Behavioural Nutrition \& Physical Activity, 11, 95. doi:10.1186/s12966-014-0095-y

Popay, J., Roberts, H., Sowden, A., Petticrew, M., Arai, L., Rodgers, M., . . Duffy, S. (2006). Guidance on the conduct of narrative synthesis in systematic reviews. A product from the ESRC Methods Programme (Unpublished Report). University of Lancaster.

Proimos, J., \& Klein, J. D. (2012). Noncommunicable diseases in children and adolescents. Paediatrics, 130(3), 379-381. doi:10.1542/peds.2012-1475

Rathmann, K., Ottova, V., Hurrelmann, K., de Looze, M., Levin, K., Molcho, M., . . . Richter, M. (2015). Macro-level determinants of young people's subjective health and health inequalities: A multilevel analysis in 27 welfare states. Maturitas, 80 , 414-420. doi:10.1016/j.maturitas.2015.01.008

Ray, C., Kalland, M., Lehto, R., \& Roos, E. (2013). Does parental warmth and responsiveness moderate the associations between parenting practices and children's health-related behaviours? Journal of Nutrition Education \& Behaviour, 45(6), 602-610. doi:10.1016/j.jneb.2013.04.001

Ray, C., \& Roos, E. (2012). Family characteristics predicting favourable changes in 10 and 11 year old children's lifestyle-related health behaviours during an 18-month follow-up. Appetite, 58, 326-332. doi:10.1016/j.appet.2011.10.009

Reitzle, M., Winkler-Metzke, C., \& Steinhausen, H. C. (2001). Parents and children: The Zurich brief questionnaire for the assessment of parental behaviours. Diagnostica, 47, 196-207. doi:10.1026//0012-1924.47.4.196

Rew, L., Arheart, K. L., Thompson, S., \& Johnson, K. (2013). Predictors of adolescents' health-promoting behaviours guided by primary socialisation theory. Journal for Specialists in Paediatric Nursing, 18, 277-288.

Rinaldi, C. M., \& Howe, N. (2012). Mothers' and fathers' parenting styles and associations with toddlers' externalising, internalising and adaptive behaviours. Early Childhood Research Quarterly, 27, 266-273. doi:10.1016/j.ecresq.2011.08.001

Roman, N. V., \& Frantz, J. M. (2013). The prevalence of intimate partner violence in the family: A systematic review of the implications for adolescents in Africa. Family Practice, 30(3), 256-266. doi:10.1093/fampra/cmso84

Ryan, S. M., Jorm, A. F., \& Lubman, D. I. (2010). Parenting factors associated with reduced alcohol use: A systematic review of longitudinal studies. Australian and New Zealand Journal of Psychiatry, 44, 774-783. doi:10.1080/00048674.2010.501759

Sleet, D. A., Gielen, A. C., Diekman, S., \& Ikeda, R. (2010). Preventing unintentional injury: A review of behaviour change theories for primary care. American Journal of Lifestyle Medicine, 4, 25-31. doi:10.1177/1559827609349573

Smith, L. H. (2011). Piloting the use of teen mentors to promote a healthy diet and physical activity among children in Appalachia. Journal of Specialised Paediatric Nursing, 16, 16-26. doi:10.1111/j.1744-6155.2010.00264.x

Smith, L. H., \& Holloman, C. (2013). Comparing the effects of teen mentors to adult teachers on child lifestyle behaviours and health outcomes in Appalachia. Journal of School Nursing, 29, 386-396. doi:10.1177/1059840512472708

Strayhorn, J. M., \& Weidman, C. S. (1988). A parenting practices scale and its relation to parent and child mental health. Journal of the American Child \& Adolescent Psychiatry, 27(5), 613-618. doi:10.1097/00004583-198809000-00016 
Tagoe, H. A., \& Dake, F. A. A. (2011). Healthy lifestyle behaviour among Ghanaian adults in the phase of a health policy change. Globalisation and Health, 7, 7-16. doi:10.1186/1744-8603-7-7

Taylor, J., \& Turner, R. J. (2001). A longitudinal study of the role and significance of mattering to others for depressive symptoms. Journal of Health and Social Behaviour, 42, 310-325. doi:10.2307/3090217

Terre, L. (2007). Behavioural medicine review: The lifestyle factor. American Journal of Lifestyle Medicine, 1, 181-184. doi:10.1177/1559827607299652

Wang, D., Ou, C., Chen, M., \& Duan, N. (2009). Health-promoting lifestyles of university students in Mainland China. BMC Public Health, 9, 1-9. doi:10.1186/1471-2458-9379

Wong, S. T. (2006). The relationship between parent emotion, parent behaviour, and health status of young African American and Latino children. Journal of Paediatric Nursing, 21(6), 434-442. doi:10.1016/j.pedn.2006.05.002

Wong, W. C., Cheung, C. S., \& Hart, G. J. (2008). Development of a quality assessment tool for systematic reviews of observational studies (QATSO) of HIV prevalence in men having sex with men and associated risk behaviours. Emerging Themes in Epidemiology, 5, 23-27. doi:10.1186/1742-7622-5-23

World Health Organization. (2006). Constitution of the World Health Organization. Geneva, Switerzland: Author 